(c) American Dairy Science Association, 2003.

\title{
Bovine Leukemia Virus Alters Growth Properties and Casein Synthesis in Mammary Epithelial Cells
}

\author{
D. D. Motton and G. C. Buehring \\ Infectious Diseases Division, School of Public Health, \\ University of California, Berkeley 94720
}

\begin{abstract}
Bovine leukemia virus (BLV) is widespread in US dairy herds, yet only about $1 \%$ of infected cattle develop bovine leukosis and are culled from the herd. A major concern is whether BLV infection of dairy cows alters milk yield. Although several studies have examined the effect of BLV on milk production in vivo, the results were inconclusive. No in vitro studies have been done. The discovery of BLV in mammary epithelial cells (MEC) of infected cows raises the possibility that the virus could affect these cells directly. The purpose of this study was to use an in vitro system to determine if BLV could alter milk yield by altering cell number and/or milk production per cell. A shortterm cell line established from the MEC of a BLVnegative cow, and a proven casein-producer mouse cell line, Comma D, were stably transfected with a plasmid containing the entire BLV genome. Untransfected parental lines served as negative controls. The BLV-containing bovine MEC line has a reduced populationdoubling time, higher saturation density, and increased longevity. The Comma D line is an alreadytransformed cell line, and growth properties did not change after transfection with BLV. Under appropriate differentiation conditions, both the bovine and mouse MEC transfected with BLV displayed decreased casein production and mRNA synthesis compared with control cell lines without BLV. Our results suggest that effects of BLV infection on milk production may not be related solely to overall animal health but may also be mediated directly at a cellular level.
\end{abstract}

(Key words: bovine leukemia virus, casein, mammary epithelial cell)

Abbreviation key: BLV = bovine leukemia virus, DMEM = Dulbecco's modified Eagle's medium, DPBS = Dulbecco's phosphate-buffered saline, $\mathbf{F B S}=$ fetal bovine serum, FHS = fetal horse serum, GAPDH =

Received June 7, 2002.

Accepted January 2, 2003.

Corresponding author: G. Buehring; e-mail: buehring@uclink4. berkeley.edu. glyceraldehyde-3-phosphate dehydrogenase, HTLV = human T-cell leukemia virus, MMLV-RT = Moloney murine leukemia virus reverse transcriptase, RT = reverse transcriptase, $\mathbf{S T V}=$ saline, trypsin, Versene.

\section{INTRODUCTION}

Bovine leukemia virus (BLV) is an oncogenic retrovirus that infects approximately $66 \%$ of all dairy cattle and $14 \%$ of all beef cattle in the United States (NAHMS, 1996). Transmission of BLV from animal to animal can occur through blood or secretions. In the cattle industry today, transmission is mainly through iatrogenic transfer of blood lymphocytes by the repeated use of veterinary and agricultural instruments without disinfection between animals (Kettman et al., 1994). Biting insects may also be responsible for bloodborne transmission. The BLV particles are found in the colostrum and milk of infected animals, and the virus can be transmitted from mother to offspring by nursing (Kettman et al., 1994). This suggests a strong relationship between BLV and lactation.

Like all retroviruses, BLV has the three major genes-gag, pol, and env-coding for the capsid, polymerase, and envelope proteins, respectively. Unlike most oncogenic retroviruses, BLV and other members of the human T-cell leukemia virus (HTLV) family genome contain an additional gene called tax. Several lines of evidence indicate tax is the region of the BLV genome necessary for tumorigenesis in vivo (Willems et al., 1998). The tax protein is a transactivating oncoprotein; tax has no obvious homology to cellular oncogenes, nor does it transform by insertional mutagenesis (Kettman et al., 1994).

Approximately 1\% of BLV-infected animals develop a B-cell lymphoma and are removed from the herd. The economic loss due to BLV infection in the United States was estimated at $\$ 44$ million in 1987 (Thurmond et al., 1987). This cost was due primarily to replacement of culled animals. In addition, it has been postulated that BLV infection might incur economic loss by affecting milk production. Epidemiologic studies on milk production in BLV-infected herds have been inconclusive, some showing increased, some de- 
creased, and some equal milk production in infected vs. uninfected herds (Langston et al., 1978; Brenner et al., 1990; Detilleux et al., 1991; Jacobs et al., 1991; D'Angelino et al., 1998). The assumption has been that a decrease in milk production would occur through generalized ill health of the animal.

The discovery that BLV infects mammary epithelial cells (Buehring et al., 1994a) raises the possibility that the virus could affect milk production directly at a cellular level. To date, there have been no studies on the effects of BLV on mammary epithelial cell function in vitro. The purpose of this study was to investigate with a cell culture system the cellular and molecular effects of BLV on the mitogenesis and lactogenesis of bovine mammary epithelial cells. We looked at whether the virus could increase the number of mammary epithelial cells by increasing growth rate or longevity, cellular changes characteristic of infection by many oncogenic viruses. Milk production would increase in proportion to the increased cell number. We also investigated whether the virus might alter levels of receptors for the mitogenic and lactogenic hormones, which, in turn, could affect both cell number and milk production per cell. Finally, we studied whether the virus might directly affect the genes for milk proteins, causing either up- or down-regulation. Hopefully, our in vitro results will enhance understanding of the effects of BLV on milk production in vivo.

\section{MATERIALS AND METHODS}

\section{Cell Lines and Cell Culture}

A short-term bovine mammary cell line, C72, was developed from a mammary gland explant from a slaughtered, 18- to-24-mo-old BLV-negative Brown Swiss heifer. The tissue was excised from the dorsal anterior portion of the front right mammary gland. The explant was digested with a mixture of collagenase (216 U/ml; ICN, Cleveland, $\mathrm{OH}$ ) and hyaluronidase (109 U/ml; Sigma Chemical Co., St. Louis, MO) overnight at $37^{\circ} \mathrm{C}$ on a shaking water bath. The cells were then pelleted and seeded into maintenance medium. During the first several passages selective procedures were used to eliminate nonepithelial cell types. Nonadherent leukocytes were eliminated in spent culture medium. Fibroblasts detached after a few minutes of treatment with STV (per milliliter, $8 \mathrm{mg}$ of $\mathrm{NaCl}, 40$ $\mu \mathrm{g}$ of KCl, $1 \mathrm{mg}$ of dextrose, $0.5 \mathrm{mg}$ of 1:250 trypsin, $0.6 \mathrm{mg}$ of $\mathrm{NaHCO}_{3}, 0.25 \mathrm{mg}$ of EDTA; and $1 \mathrm{ml}$ of $1 \%$ phenol red), leaving epithelial cells, which required at least $10 \mathrm{~min}$ to detach. The other cell line used was Comma D, a well-characterized mouse mammary epithelial cell line (Danielson et al., 1984), extensively used for CN gene expression studies.
All cell lines were maintained as monolayers at $37^{\circ} \mathrm{C}$ in $5 \% \mathrm{CO}_{2}$ under humid conditions on either 25 or 75 $\mathrm{cm}^{2}$ culture flasks (Corning Life Sciences, Acton, MA). Maintenance medium for bovine cell lines was Dulbecco's modified Eagles medium (DMEM)-high glucose, (Gibco BRL, Carlsbad, CA), supplemented with the following (per milliliter): $10 \mu \mathrm{g}$ of insulin (Sigma), 10 $\mu \mathrm{g}$ of gentamicin (Sigma), $6.5 \mu \mathrm{g}$ of polymixin B sulfate (Sigma), $100 \mu \mathrm{g}$ of streptomycin sulfate (Sigma), 253.5 $\mathrm{U}$ of penicillin G (Sigma), $2.5 \mu \mathrm{g}$ of amphotericin B (Sigma), $290 \mu \mathrm{g}$ of L-glutamine (ICN), and 10\% fetal bovine serum [FBS (Omega Scientific, Tarzana, CA)]. Maintenance medium for the Comma D cell was a 1:1 mixture of DMEM-high glucose, (Gibco BRL): Hams F-12 (Sigma) media containing the above supplements, as well as (per milliliter) $5 \mu \mathrm{g}$ of transferrin (Sigma), $5 \mathrm{ng}$ of epidermal growth factor (EGF, Sigma), $5 \mathrm{ng}$ of sodium selenite (Difco Laboratories, Detroit, MI), and 2\% FBS (Omega Scientific). Culture fluids were changed approximately every $4 \mathrm{~d}$, and cells passaged at confluence. Both cell lines were negative for Mycoplasma by the Hoescht method (Freshney, 2000).

Because the explant contained a mixture of several cell types, the final cell line obtained was characterized for markers representing different cell types: keratin for epithelial cells, smooth muscle actin for myoepithelial cells, vimentin for fibroblasts, and esterase for macrophages. For immunocytochemistry to detect keratin, vimentin, and actin, cells were seeded into wells of a 96-well plate, allowed to attach overnight, then fixed with $10 \%$ buffered formalin (10\%, wt/vol $37 \%$ formaldehyde, in Dulbecco's PBS without calcium or magnesium [DPBS]). After fixation, cells were blocked for $30 \mathrm{~min}$ in buffer (DPBS) with $1.5 \%$ fetal horse serum (FHS), (Cansera, Etobicoke, Ontario) and 1\% hydrogen peroxide, in order to quench any endogenous peroxidase activity. Cells were incubated $1 \mathrm{~h}$ with either rabbit anti-bovine cytokeratins (Dako, Carpinteria, CA), diluted 1:250 by manufacturer; mouse antihuman smooth muscle actin (Dako), which reacts with smooth muscle actin from a number of species including bovine, diluted 1:100 in buffer with 1.5\% FHS; or mouse anti-bovine vimentin (ICN), diluted 1:100 in buffer with $1.5 \%$ FHS. Secondary antibody, either biotinylated goat anti-rabbit (Vector Laboratories, Burlingame, CA) or biotinylated horse anti-mouse (Vector Laboratories), diluted 1:200 in buffer with 1.5\% FHS, was incubated with cells for $1 \mathrm{~h}$. Amplification was 30 min with Vectastain $\mathrm{ABC}$ reagent (an avidin-biotinperoxidase conjugate, Vector Laboratories) according to manufacturer's instructions. After amplification, antibody binding and amplification were visualized using 3,3'-diaminobenzidine (Sigma), prepared according to manufacturers instructions. After each step 
cells were given three brief rinses and one 10-min rinse with DPBS. Cells were stained for the presence of esterase as described previously (Buehring, 1990).

For evaluation of morphology, monolayers of C72/ $\mathrm{Neo}$ and C72/BLV cell lines were fixed for $30 \mathrm{~min}$ in methanol, stained for approximately $20 \mathrm{~min}$ with Giemsa stain diluted 1:25 in water, then washed 3 times with water. Monolayers were photographed with a SPOT reverse transcriptase (RT) camera (Diagnostic Instruments, Inc., Sterling Heights, MI) mounted on a Nikon TE300 compound microscope (Nikon, Tokyo, Japan).

\section{Transfections and Cloning}

Transfections were done using two plasmids: pBLV (Derse and Casey, 1987), which contains a DNA copy of the entire BLV genome under control of its own promoter, the long terminal repeat region, and pSVneo1 (Southern and Berg, 1982), a plasmid containing the neomycin resistance gene under control of the SV40 promoter. Cell lines were either cotransfected with both pBLV and pSVneo1 or with just pSVneo1, using $20 \mu \mathrm{g}$ of Lipofectamine reagent (Gibco BRL), pSVneo1 at a concentration of $1.2 \mu \mathrm{g} / \mathrm{ml}$, and pBLV at a concentration of $12 \mu \mathrm{g} / \mathrm{ml}$, in DMEM or DMEM:F-12 without serum, according to the manufacturer's instructions. In cases in which only pSVneo1 was used, $10 \mu \mathrm{g} / \mathrm{ml}$ of plasmid was used. Cells were exposed to the transfection mixture for $18 \mathrm{~h}$ and then maintained on selection maintenance medium containing $0.5 \mathrm{mg} / \mathrm{ml}$ of G418 sulfate (Omega Scientific), until colonies formed. C72 was transfected at a doubling level of 25 and Comma D at a doubling level of approximately 17 .

Cloning was done by the standard limiting dilution method (Freshney, 2000) with conditioned media consisting of a 1:1 mixture of fresh DMEM and filtered spent DMEM from the same cell line. Wells were inspected microscopically, and only those containing a single cell were circled and followed. Emerging colonies were detached by STV, pelleted, rinsed in DPBS, and seeded into $25-\mathrm{cm}^{2}$ flasks. Maintenance medium for all cells thereafter contained $0.25 \mathrm{mg} / \mathrm{ml}$ of G418 sulfate.

The presence of BLV was confirmed by PCR. DNA was isolated from cells using the salting out procedure, based on a method by Miller et al. (1988). PCR was performed with $1 \mu \mathrm{g}$ of the DNA, in buffer containing $10 \mathrm{~m} M$ Tris- $\mathrm{HCl}, 50 \mathrm{~m} M \mathrm{KCl}, 0.1 \%$ Triton X-100, 1.5 $\mathrm{mM} \mathrm{MgCl} 2$ (Promega), $200 \mu M$ dNTP (Amersham), 0.8 $\mu M$ of both 5' and 3' primers, and $1.7 \mathrm{U}$ of Taq polymerase (Promega). The reaction was performed on the Perkin Elmer Cetus DNA Thermal Cycler (Norwalk, CT) model \# N801-0150. Primer sequences from within the tax region of the BLV genome were as follows: $\mathrm{BLV}$ tax 5' CTAGGTAATGGACTATTGCT, BLV tax 3' GAATCATTGCGTAGGACAGG, product size 374 bp.

\section{Growth Assays}

Cells were assayed in triplicate for growth using the CellTiter 96 AQueous Non-Radioactive Cell Proliferation Assay (Cat \# G5421; Promega) according to manufacturer's instructions. This kit is based on the method by Mosmann (1983). Cells were seeded at a concentration of 500 cells per well into a 96 -well plate. After attachment, cells were assayed for growth every $3 \mathrm{~d}$ for 2 wk. Optical density was determined using a Titertek Multiscan MCC plate reader at $492 \mathrm{~nm}$ (Titertek Instruments, Huntsville, AL) and plotted on a graph vs. time.

Doubling level was calculated as the number of times cells were passaged as a 1:2 split. Saturation density was determined according to Freshney (2000). Cells were allowed to grow to confluency in a $25-\mathrm{cm}^{2}$ flask and then maintained in the flask for $10 \mathrm{~d}$ with several medium changes to assure cells had reached maximum confluency. Monolayers were then detached with STV, and viable cells counted on a hemocytometer using trypan blue exclusion. Total cell number was divided by 25 to get cell $/ \mathrm{cm}^{2}$. Soft agar growth was performed according to Freshney (2000). A mixture of $0.5 \mathrm{ml}$ of $2 \times$ concentrated DMEM with $20 \%$ FBS and $0.5 \mathrm{ml}$ of $1.5 \%$ melted Noble-Agar (Difco) was held at $42^{\circ} \mathrm{C}$. To this, $200 \mu \mathrm{l}$ of medium containing 100 cells was added, and the resulting solution added to one well of a 24-well culture plate. After gels had solidified, DMEM was layered over the top of the gel. Cells were observed for colony growth for 2 wk. MCF-7, a human breast cancer cell line known to grow well in soft agar cultures, was used as a positive control.

\section{Radioreceptor Assays}

Whole cell radioreceptor assays were performed in triplicate according to Katzenellenbogen et al. (1987). This method is based on the quantitation of receptor binding of radiolabled hormone in whole cells. Cultured cells, detached by STV, were pelleted and resuspended in serum-free maintenance medium to a concentration of 120,000 cells $/ \mathrm{ml}$. Aliquots of $800 \mu \mathrm{l}$ of the cell suspension were incubated with 0.05 to $20 \mathrm{nM}$ of either $\left[6,7-{ }^{3} \mathrm{H}(\mathrm{N})\right]$ estradiol (New England Nuclear Laboratories, Boston, MA), $\left[1,4,6,7-{ }^{3} \mathrm{H}\right]$ progesterone (Amersham Biosciences, Piscataway, NJ), or [6,7${ }^{3} \mathrm{H}(\mathrm{N})$ ] dexamethasone (New England Nuclear Laboratories), in the presence or absence of $500 \times$ concentra- 
tion unlabeled hormone, for $30 \mathrm{~min}$ at $37^{\circ} \mathrm{C}$, in a final volume of $1 \mathrm{ml}$. Cells were then pelleted at low-speed centrifugation $(500 \times g)$, rinsed three times with icecold $1 \times$ DPBS, resuspended in $200 \mu$ l of ice cold $1 \times$ DPBS, and added to $2 \mathrm{ml}$ of scintillation fluid (Ecolite, ICN). One milliliter of ethanol was added to better solubilize hormone, and samples were counted on a Beckman LS 6000IC scintillation counter (Beckman Coulter Inc., Fullerton, CA).

\section{Collagen Gel Cultures}

Collagen gel cultures were set up according to Talhouk et al. (1993). Rat tail collagen (Becton Dickinson Labware, Bedford, MA) was prepared to a final concentration of $0.5 \mathrm{mg} / \mathrm{ml}$ according to manufacturer's instructions using a $1 \mathrm{~N}$ solution of $\mathrm{NaOH}$. Gels were cast into wells of a 24-well plate at $500 \mu \mathrm{l} /$ well, then solidified for $30 \mathrm{~min}$ at $37^{\circ} \mathrm{C}$ and equilibrated with maintenance medium for either $4 \mathrm{~h}$ at $37^{\circ} \mathrm{C}$ or overnight at $4^{\circ} \mathrm{C}$. After equilibration, mammary epithelial cells in maintenance medium were plated onto gels at a concentration of $5 \times 10^{5}$ cells/well and incubated for $24 \mathrm{~h}$ at $37^{\circ} \mathrm{C}$. After attachment, $1 \mathrm{ml}$ of appropriate maintenance medium for each cell line, supplemented with $5 \mu \mathrm{g} / \mathrm{ml}$ of hydrocortisone (Sigma), $10 \mu \mathrm{g} / \mathrm{ml}$ of prolactin (Sigma), and 15\% FBS, was added to each culture. Gels were rendered free-floating by rimming with a pasteur pipette.

\section{Western Blots (Immunoblots)}

Western blots were performed according to a modified protocol of Sambrook et al. (1989). Cellular lysates were obtained in duplicate, every $2 \mathrm{~d}$ using CAT assay lysis buffer (Roche Molecular Bioproducts, Indianapolis, IN) according to manufacturer's instructions. The collagen gels were not degraded by this process. Lysates were centrifuged for $1 \mathrm{~min}$ at $8000 \times g$ to remove any particulate matter. Lysates were first mixed 1:1 with $2 \times$ concentrated SDS-PAGE electrophoresis sample buffer (0.125 $M$ Tris-HCl, 4\% SDS, $20 \%$ glycerol, $10 \%$ 2-mercaptoethanol, $0.2 \mathrm{mg}$ of bromphenol blue, $\mathrm{pH}$ 6.8), boiled for $2 \mathrm{~min}$, and loaded onto a 10\% SDSPAGE gel. Positive control was either bovine CN, 10 $\mu \mathrm{g} / \mathrm{ml}$ (Sigma), or mouse CN, $36 \mu \mathrm{g} / \mathrm{ml}$. Gels were electrophoresed for $15 \mathrm{~min}$ at $80 \mathrm{~V}$, then $1 \mathrm{~h}$ at $150 \mathrm{~V}$ in Tris-glycine electrophoresis buffer ( $25 \mathrm{~m} M$ Tris-HCl, $250 \mathrm{mM}$ glycine, $0.1 \% \mathrm{SDS}$ ). The gel was formed on a Hoeffer "Mighty Small II" vertical gel apparatus (Amersham Biosciences). After electrophoresis, the gel was equilibrated in transfer buffer ( $39 \mathrm{~m} M$ glycine, $48 \mathrm{mM}$ Tris base, $0.037 \%$ SDS, $20 \%$ methanol) for $30 \mathrm{~min}$. The gel was then transferred to a $0.45-\mu \mathrm{m}$ thick nitrocellu- lose membrane (Osmonics, Westborough, MA) for 30 min at $40 \mathrm{~V}$ on a Transblot SD Semi-Dry Transfer Cell (BioRad Laboratories, Richmond, CA). After transfer, membranes were allowed to dry overnight, and then stained with $0.1 \%$ Ponceau S (Sigma) in 5\% acetic acid to determine whether protein transfer had occurred. After staining, membranes were washed twice in water.

For bovine cellular lysates, membranes were blocked overnight at $4^{\circ} \mathrm{C}$ in wash buffer $(25 \mathrm{~m} M$ Tris base, $200 \mathrm{~m} M \mathrm{NaCl}, 3 \mathrm{mM} \mathrm{KCl}, \mathrm{pH} 7.4$, with $0.1 \%$ Tween 20; Fisher, Santa Clara, CA) and 3\% normal rabbit serum (Vector Laboratories). After blocking, membranes were washed 4 times, 10 min each in wash buffer. The membrane was then incubated with primary antibody, polyclonal sheep anti-bovine CN (Biogenesis Inc, Brentwood, NH), diluted 1:5000 in wash buffer, for $1.5 \mathrm{~h}$ at room temperature. The membrane was then washed 4 times, 10 min each in wash buffer, and incubated with secondary antibody, biotinylated rabbit anti-sheep (Vector Labs), diluted 1:5000 in wash buffer followed by washing 4 times, 10 min each in wash buffer. Amplification used streptavidin-horseradish-peroxidase (strept-HRP; Amersham Biosciences) diluted 1:3000 in wash buffer and reacted for $1 \mathrm{~h}$ at room temperature. Antibody binding was detected by incubating the blot with ECL Western blotting chemiluminescent detection reagents (ECL; Amersham Biosciences) for approximately $1 \mathrm{~min}$, according to manufacturer's instructions. The membranes were then exposed to Hyperfilm ECL (Amersham Biosciences) for 10 to $30 \mathrm{~s}$. Film was developed on a Konica model SRX-101 film processor (Konica Corporation, Tokyo, Japan).

For mouse cellular lysates, Western blots were performed as above, except that blocking buffer contained $5 \%$ fetal horse serum (Cansera). The primary antibody was mouse anti-rat alpha $a_{\mathrm{s} 1} \mathrm{CN}$ monoclonal antibody, diluted 1:5000 in wash buffer. The secondary antibody was biotinylated horse anti-mouse (Vector Labs), diluted 1:5000 in wash buffer.

\section{Enzyme-Linked Immunosorbent Assays}

The concentration of $\mathrm{CN}$ in cellular lysates was quantified by enzyme-linked immunosorbent assay (ELISA). ELISA 96-well plates (Nunc-Immuno Plate MaxiSorp Surface; Nalge Nunc International, Rochester, NY) were coated with cellular lysates from either bovine or mouse cells, mixed 1:10 with coating buffer (15 $\mathrm{m} M \mathrm{Na}_{2} \mathrm{CO}_{3}, 30 \mathrm{mM} \mathrm{NaHCO} 3,10 \% \mathrm{NaN}_{3}, \mathrm{pH}$ 9) and incubated overnight at $4^{\circ} \mathrm{C}$. Either bovine $\mathrm{CN}$ (Sigma) or mouse CN were also diluted 1:10 in coating buffer and used as standards in each assay. After incu- 
bation and removal of samples, the plate was washed three times with wash buffer (DPBS with $0.1 \%$ Tween 20 ). For bovine lysates, polyclonal sheep anti-bovine CN (Biogenesis) diluted 1:3000 in wash buffer was added to the wells and incubated for $1 \mathrm{~h}$. The plate was then washed three times with wash buffer. Secondary antibody, biotinylated rabbit anti-sheep (Vector Labs) diluted 1:1000, was incubated $1 \mathrm{~h}$. The wells were again washed three times with wash buffer. Amplification was performed by incubating wells for $1 \mathrm{~h}$ with strept-HRP (Amersham) diluted 1:1000 in wash buffer. The wells were washed three times with wash buffer, then $100 \mu$ l of o-phenylenediamine dihydrochloride (Sigma), made up per manufacturer's instructions, was added and allowed to incubate $20 \mathrm{~min}$. Optical density was read on the Titertek Multiscan MCC plate reader at $450 \mathrm{~nm}$ (Titertek Instruments). Fresh media diluted 1:10 in coating buffer was used as a negative control.

For mouse cellular lysates, ELISA was performed as above except primary antibody was mouse anti-rat alpha-s1 CN monoclonal antibody diluted 1:3000 in wash buffer, and secondary antibody was biotinylated horse anti-mouse (Vector Labs), diluted 1:1000 in wash buffer. Casein concentrations were normalized per DNA concentration for each sample using the Hoechst method (Freshney, 2000).

\section{Reverse Transcription-PCR}

Total RNA was isolated from either mouse or bovine mammary epithelial cells on floating collagen gels using the Qiagen RNeasy Mini Kit (\# 74104; Qiagen, Valencia, CA) according to manufacturer's instructions. RNA was stored at $-80^{\circ} \mathrm{C}$ until use.

Before we used RNA samples in a RT reaction, samples were treated with RQ1 RNase-Free DNase (Promega) according to manufacturer's instructions, to remove any trace of genomic DNA that may have been carried over during RNA isolation. Reverse transcription of RNA into cDNA was performed using Moloney murine leukemia virus reverse transcriptase (MMLVRT' Promega). For each sample, approximately $1 \mu \mathrm{g}$ of RNA, $40 \mathrm{U}$ of recombinant RNasin (Promega) and $0.5 \mu \mathrm{g}$ of oligo (dT) 15 primer (Promega) were mixed and incubated at $65^{\circ} \mathrm{C}$ for $5 \mathrm{~min}$ and then put on ice for $5 \mathrm{~min}$. To this, $38 \mu \mathrm{l}$ of a mixture containing 50 $\mathrm{m} M$ Tris- $\mathrm{HCl}, 75 \mathrm{~m} M \mathrm{KCl}, 3 \mathrm{~m} M \mathrm{MgCl}_{2}, 10 \mathrm{~m} M$ dithiothreitol, $200 \mu M$ dNTPs (Amersham) and $60 \mathrm{U}$ of MMLV-RT was added. This reaction was incubated for $1 \mathrm{~h}$ at $37^{\circ} \mathrm{C}$. MMLV-RT was inactivated by incubating at $70^{\circ} \mathrm{C}$ for $10 \mathrm{~min}$. Reactions with no RT, no RNA, or no primer were used as negative controls.
Polymerase chain reaction was performed using 2 $\mu \mathrm{l}$ of the resulting cDNA solution, in buffer containing $10 \mathrm{~m} M$ Tris- $\mathrm{HCl}(\mathrm{pH}), 50 \mathrm{~m} M \mathrm{KCl}, 0.1 \%$ Triton $\mathrm{X}-100$, $1.5 \mathrm{mM} \mathrm{MgCl}{ }_{2}$ (Promega), $200 \mu M$ dNTP (Amersham), $0.8 \mu M$ of both 5' and 3' primers, and $1.7 \mathrm{U}$ of Taq polymerase (Promega). The reaction was performed on the GeneAmp PCR System 2700 thermal cycler (Applied Biosystems, Foster City, CA). Reactions with no template or with RNA were used as negative controls. Primer sequences were as follows:

Bovine glyceraldehyde-3-phosphate dehydrogenase (GAPDH) 5' primer: CCTTCATTGACCTTCACTACA TGGTCTA, bovine GAPDH 3' primer: GCTGTAGCC AAATTCATTGTCGTACCA, product size 857 bp. Bovine $\mathrm{CN} 5^{\prime}$ primer: AGAGAGCTGGAAGAACTCAAT GTACCGGGTGAG, Bovine CN 3' primer: TTAGACA ATAATAGGGAAAGGTCCCCGGACAGG, product size $630 \mathrm{bp}$. Mouse GAPDH 5' primer: AGCTTGTCA TCAACGGGAAG, mouse GAPDH $3^{\prime}$ primer: ATGTA GGCCATGAGGTCCAC, product size 796 bp. Mouse CN 5' primer: CTTGCAAGAGAGACTACATTTACT, mouse CN 3' primer: TTAAGAAGTTCTAGGTACTG CAGA, product size $608 \mathrm{bp}$.

\section{Statistical Analysis}

Growth characteristics and receptor levels and affinities were analyzed for statistical differences using the Dunnett $t$ test. This test allows comparisons of multiple experiment groups with one control group using a pooled standard deviation. Minimum significance was $P \leq 0.05$.

\section{RESULTS}

\section{Growth Characteristics and Immortalization of Cells by BLV}

After transfection of BLV into the short-term cell line, C72, resistant cells apparent after approximately $4 \mathrm{wk}$ of selection were cloned with an efficiency of approximately $15 \%$. Four clones were developed, but the two best growing, C72/BLV1 and C72/BLV3, were used for subsequent experiments. In contrast, the control line, $\mathrm{C} 72 / \mathrm{Neo}$, containing only the neomycin resistance plasmid, had a cloning efficiency of approximately $2 \%$, with none of the clones developing into lines. The $\mathrm{C} 72 / \mathrm{Neo}$ clones senesced within 2 to $3 \mathrm{wk}$, after small colonies had formed (approximately 200 to 300 cells) but before those colonies could be expanded. The C72/Neo used as a control for subsequent experiments was not a clone but, rather, a population of cells containing the pSVNeo plasmid and selected for with G418 sulfate. The presence of BLV in the C72/BLV lines was confirmed by PCR detection of the unique 
Table 1. Growth characteristics of mammary epithelial cells with and without bovine leukemia virus. Data presented is the mean of triplicate cultures.

\begin{tabular}{lclcl}
\hline & $\begin{array}{l}\text { Population } \\
\text { doubling level }\end{array}$ & $\begin{array}{l}\text { Population } \\
\text { doubling time }(\mathrm{h})\end{array}$ & $\begin{array}{l}\text { Saturation density } \\
\text { cells/cm }{ }^{2}\end{array}$ & $\begin{array}{c}\text { Growth } \\
\text { in agar }\end{array}$ \\
\hline C-72/Neo & 30 & $48.0 \pm 2.64$ & $43,000 \pm 2546$ & - \\
C-72/BLV & 183 & $38.4 \pm 3.12^{*}$ & $85,333 \pm 4027^{*}$ & - \\
C-72/BLV1 & 229 & $28.8 \pm 3.36^{*}$ & $76,800 \pm 6788^{*}$ & - \\
C-72/BLV3 & 208 & $28.7 \pm 2.16^{*}$ & $93,000 \pm 7071^{*}$ & - \\
Comma D/Neo & 50 & $68.1 \pm 9.6$ & $145,067 \pm 10,129$ & - \\
Comma D/BLV4 & 51 & $72.5 \pm 5.7$ & $149,600 \pm 9822$ & - \\
Comma D/BLV5 & 55 & $61.4 \pm 1.2$ & $137,210 \pm 5899$ & - \\
\hline
\end{tabular}

$* P<0.05$, Dunnett $t$ test.

tax gene (data not shown). The $\mathrm{C} 72 / \mathrm{Neo}$ cells not transfected with the BLV plasmid were negative for BLV by PCR. Cells were characterized by immunocytochemistry and nonspecific esterase staining. All cells lines isolated from bovine mammary gland were positive for epithelial cytokeratins ( $100 \%$ positive), an epithelial cell marker; negative for smooth muscle actin, a marker for myoepithelial cells; negative for vimentin, a marker for fibroblasts; and negative for the nonspecific esterase enzyme, present only in cells of monocyte and macrophage origin (data not shown).

Table 1 shows the growth characteristics for both bovine and mouse cells lines, with and without BLV. C72/BLV lines had a significantly greater longevity (population doubling level $>180$ ) compared with the control $\mathrm{C} 72 / \mathrm{Neo}$, which rarely could be cultured past a population doubling level of 30 to 40 . Cells lines with BLV showed larger nuclei and smaller cytoplasm, a morphology more characteristic of transformed cells (Figure 1B). In contrast, the $\mathrm{C} 72 / \mathrm{Neo}$ control without BLV showed the large, spreading cells with small nuclei, characteristic of senescing cells (Figure 1A; Buehring, 1990). Doubling time was reduced by approximately 10 to $20 \mathrm{~h}$ in $\mathrm{C} 72 / \mathrm{BLV}$ lines, compared with the control line $\mathrm{C} 72 / \mathrm{Neo}$, thus demonstrating a significantly increased growth rate. Saturation density for bovine cells containing BLV was significantly higher than that of the control line. Neither C72/Neo nor C72/BLV lines had the ability to grow in soft agar. Although we did not grow the Comma D cell lines past a population doubling level of 55, the parental line was found by others to be immortal (Danielson et al., 1984). The mouse cell line Comma D is already an established, immortalized cell line, at a doubling level $>100$. Doubling times for Comma D/BLV and Comma $\mathrm{D} / \mathrm{Neo}$, the control without $\mathrm{BLV}$, were similar, and the presence of BLV did not change the saturation density of these cells. Growth in agar was not tested for the Comma D cell lines since it was previously established that the Comma D cell line does not have the ability to grow in soft agar (Danielson et al., 1984). All of these
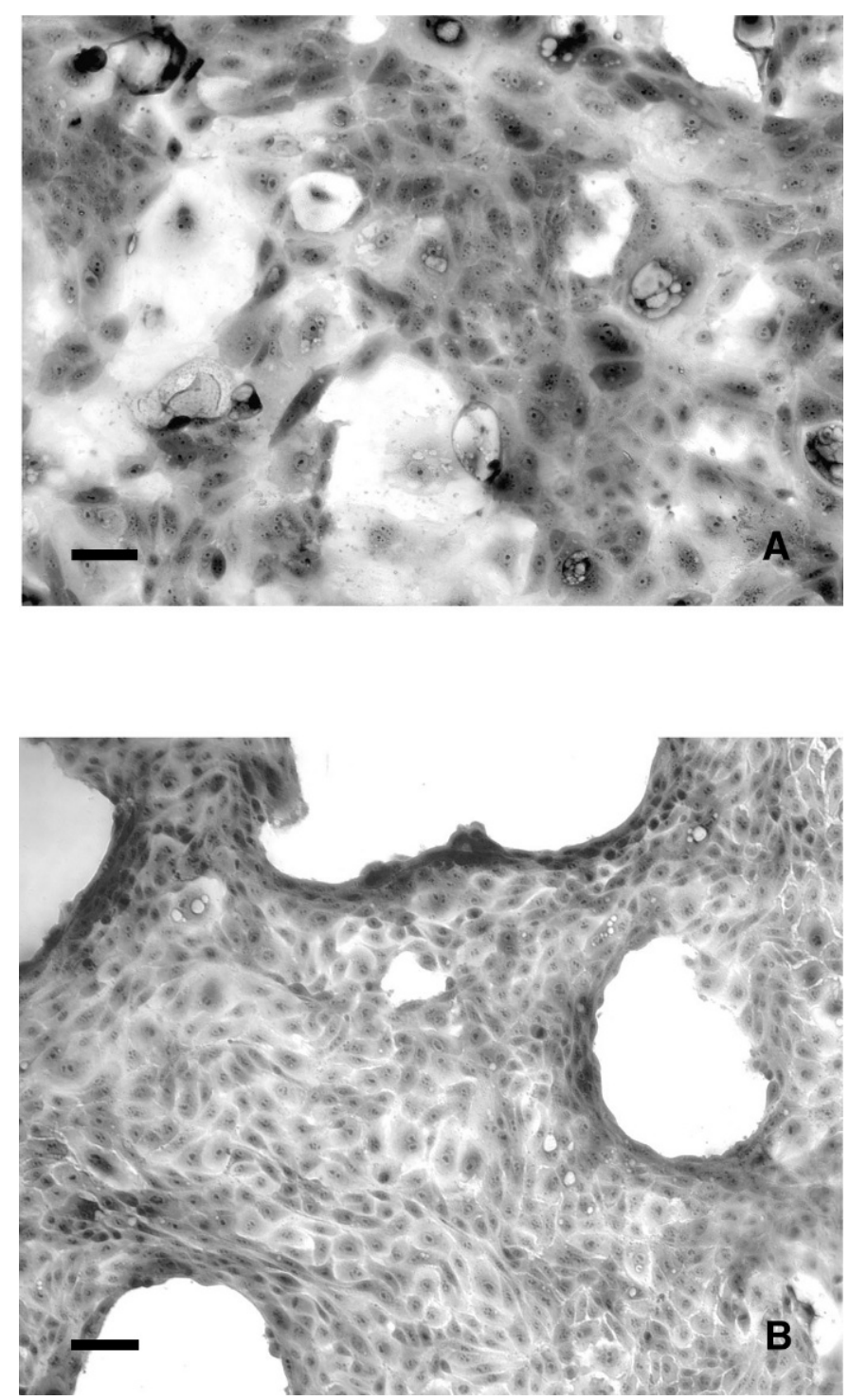

Figure 1. C72/Neo cell, without bovine leukemia virus (BLV) (A) and C72/BLV3 cells, transfected with BLV (B) stained with Giemsa stain then photographed at 400X. Note larger nuclear/cytoplasmic ratio in BLV containing cells. Scale bar $=67 \mu \mathrm{m}$. 
Table 2. Steroid hormone receptor levels and affinities in bovine mammary epithelial cells with and without bovine leukemia virus. Data presented is the mean of triplicate trials.

\begin{tabular}{|c|c|c|c|c|c|c|}
\hline & \multicolumn{2}{|c|}{ Estrogen receptor } & \multicolumn{2}{|c|}{ Progesterone receptor } & \multicolumn{2}{|c|}{ Glucocorticoid receptor } \\
\hline & $\mathrm{fmol} / 1 \times 10^{6}$ cells & $\mathrm{K}_{\mathrm{d}}(\mathrm{M})$ & $\mathrm{fmol} / 1 \times 10^{6}$ cells & $\mathrm{K}_{\mathrm{d}}(\mathrm{M})$ & $\mathrm{fmol} / 1 \times 10^{6}$ cells & $\mathrm{K}_{\mathrm{d}}(\mathrm{M})$ \\
\hline $\mathrm{C}-72 / \mathrm{Neo}$ & $27.1 \pm 7.9$ & $6.6 \times 10^{-10}$ & $16.2 \pm 7.6$ & $1.1 \times 10^{-9}$ & $89.6 \pm 11.8$ & $1.2 \times 10^{-10}$ \\
\hline C-72/BLV & $20.1 \pm 3.2$ & $2.5 \times 10^{-10}$ & $12.7 \pm 4.5$ & $1.7 \times 10^{-9}$ & $91.0 \pm 17.3$ & $4.7 \times 10^{-9}$ \\
\hline C-72/BLV1 & $33.8 \pm 5.7$ & $3.0 \times 10^{-9}$ & $6.7 \pm 1.6$ & $1.9 \times 10^{-9}$ & $123.5 \pm 24$ & $6.9 \times 10^{-9}$ \\
\hline C-72/BLV3 & $56.5 \pm 2.9^{*}$ & $9.6 \times 10^{-9}$ & $10.6 \pm 3.7$ & $5.3 \times 10^{-10}$ & $96.7 \pm 14.3$ & $9.9 \times 10^{-9}$ \\
\hline
\end{tabular}

$* P<0.05$, Dunnett $t$ test.

parameters (doubling level, doubling time, saturation density, and growth in soft agar) are in vitro indicators of transformation (Freshney, 2000). These assays were repeated two to three times.

\section{Steroid Receptor Levels and Affinities}

Table 2 shows total estrogen, progesterone, and glucocorticoid receptor levels and affinities in C72 bovine cell lines. All receptor levels and affinities for cells containing BLV were similar as compared with the control cell line without BLV (C72/Neo), except C72/ BLV3, which had a more elevated estrogen receptor level $\left(56.5 \pm 2.9 \mathrm{fmol} / 1 \times 10^{6}\right.$ cells $)$ than $\mathrm{C} 72 / \mathrm{Neo}(27.1 \pm$ $7.9 \mathrm{fmol} / 1 \times 10^{6}$ cells). All experiments were performed three separate times in triplicate. The increased estrogen receptor levels in $\mathrm{C} 72 / \mathrm{BLV}_{3}$ did not confer an increase in proliferation rate in response to estrogen $(0$ to $200 \mathrm{n} M$ ) in maintenance medium (DMEM) supplemented with either 10\% FBS or 10\% FBS stripped of endogenous steroids by charcoal treatment (data not shown).

\section{Detection of $\mathrm{CN}$ in Cellular Lysates by Immunoblot (Western Blot)}

We measured $\mathrm{CN}$ production as an indication of whether BLV could have an effect on the ability of the mammary epithelial cell to synthesize milk proteins. Figure 2 shows the results of Western blots of cellular lysates from cell lines with and without BLV, over a period of $8 \mathrm{~d}$. All cells were grown under the same hormonal conditions (prolactin, hydrocortisone, and insulin), on a collagen matrix. Both control cell types, C72/Neo (Figure 2A) and Comma D/Neo (Figure 2C) produced appreciable amounts of $\mathrm{CN}$, with the concentration tapering off towards the 8-d time point. We were able to detect only very low levels of $\mathrm{CN}$ in any cell type containing BLV. Each collagen gel assay was performed two times for each cell line, with each time point done in duplicate. Two Western blots for each cell line were done, Figure 2 representing the best for each cell line.

\section{Quantification of CN from Cellular Lysates by ELISA}

To confirm the results from the Western blots, and to quantify the amounts of CN being produced, ELISA was performed using the same cellular lysates used for the Western blots. Figure 3 shows the results of the ELISA on the lysates from $\mathrm{C} 72 / \mathrm{Neo}, \mathrm{C} 72 / \mathrm{BLV}$, C72/BLV1, C72/BLV3. Casein amounts were normalized per amount of DNA in culture at the time lysates were collected. Because DNA concentration is directly proportional to cell number, normalization controls for the increased cell number that may occur in cells transfected with BLV. In the ELISA assay all cell clones containing BLV demonstrated an initial slight production of $\mathrm{CN}$, around d 4, which subsequently declined to even lower levels. The BLV containing cells also maintained a very similar pattern of $\mathrm{CN}$ production when compared to each other. In contrast, C72/ $\mathrm{Neo}$, the control cell line without BLV, produced significant amounts of $\mathrm{CN}$ starting at $\mathrm{d} 4$, and continuing to rise and peak at a concentration of about $78 \mathrm{ng}$ of CN per microgram of DNA on d 10. Casein production started to drop right after this and was lower at d 14 . This corresponded to a period when cell death became significant (data not shown). The pattern of CN production by cells did not change when results were normalized for DNA content. Figure 4 depicts $\mathrm{CN}$ production by Comma D cell lines. Comma D/BLV4 and Comma D/BLV5 also produced a much lower amount of $\mathrm{CN}$, as seen in the western blot, than the control cells, Comma D/Neo. The pattern of $\mathrm{CN}$ production in Comma D/Neo was different compared with that of bovine cells. The control mouse cells, Comma D/Neo, produced a significant amount of CN early in culture, around $\mathrm{d} 2$, and then this decreased as time went on. The Comma D/BLV4 and Comma D/BLV5 produced less CN, and what was seen, was early, around $d 2$ or 4 of culture. All ELISA were performed in triplicate and repeated twice.

\section{Detection of CN mRNA by RT-PCR}

To determine whether BLV were affecting CN production at the level of transcription, an $\mathrm{RT}$ reaction 

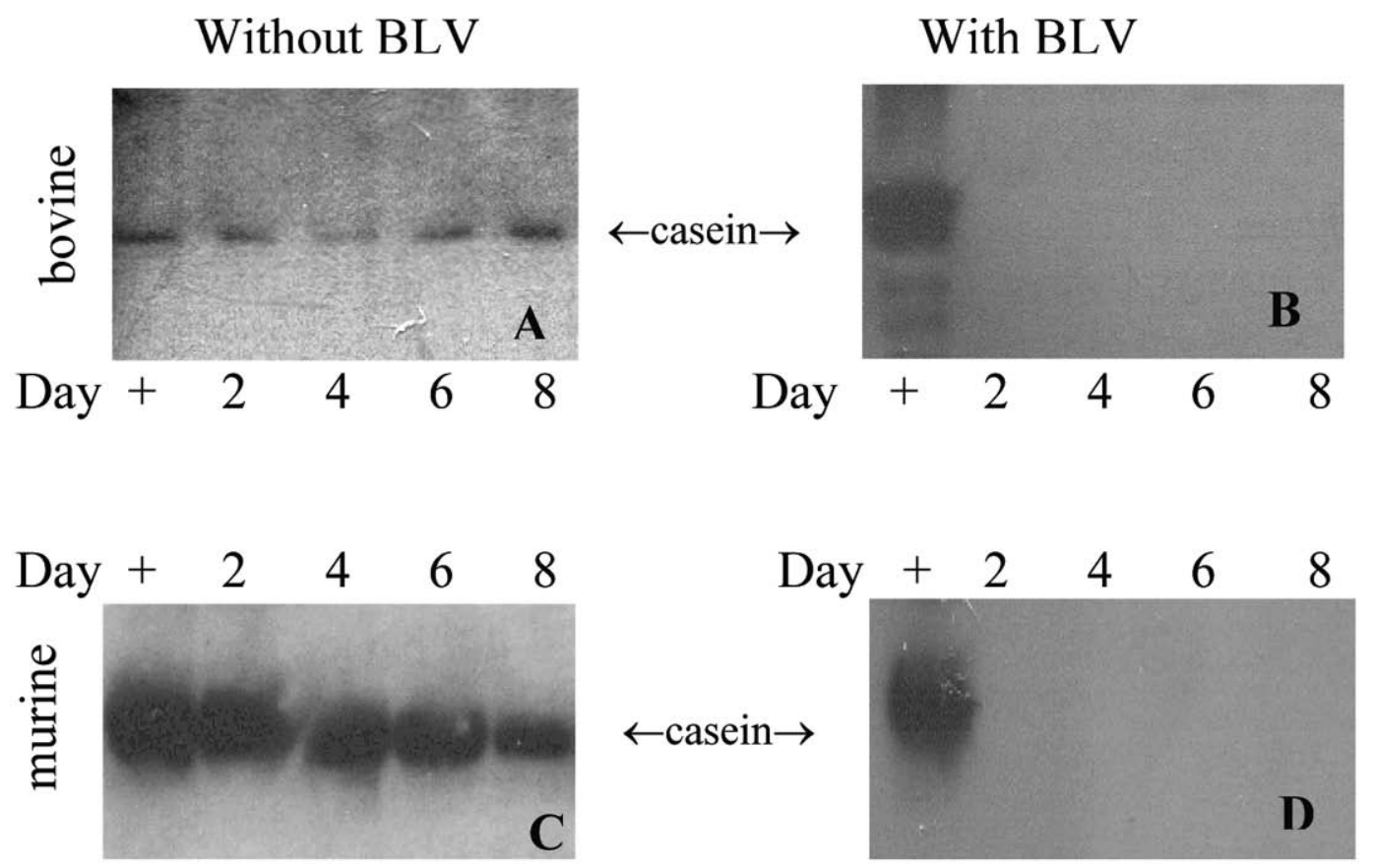

Figure 2. Western blot measurement of $\mathrm{CN}$ in lysates of mammary epithelial cells with and without bovine leukemia virus (BLV). Mammary cells with and without BLV were seeded onto collagen gels and incubated with lactogenic hormones, prolactin, hydrocortisone, and insulin. Cellular lysates were collected every $2 \mathrm{~d}$ and analyzed on Western blot. (+) represents the positive control of either bovine CN or mouse CN. (A) C72/Neo; (B) Western blot representative of all bovine mammary cells with BLV: C72/BLV, C72/BLV1, C72/BLV3; (C) Comma D/Neo; and (D) Western blot representative of all mouse mammary cells with BLV: Comma D/BLV4, Comma D/BLV5.

was performed on RNA isolated from cells grown in differentiation conditions in culture, that is, on floating collagen gels in the presence of the lactogenic hormones prolactin, hydrocortisone, and insulin. PCR for

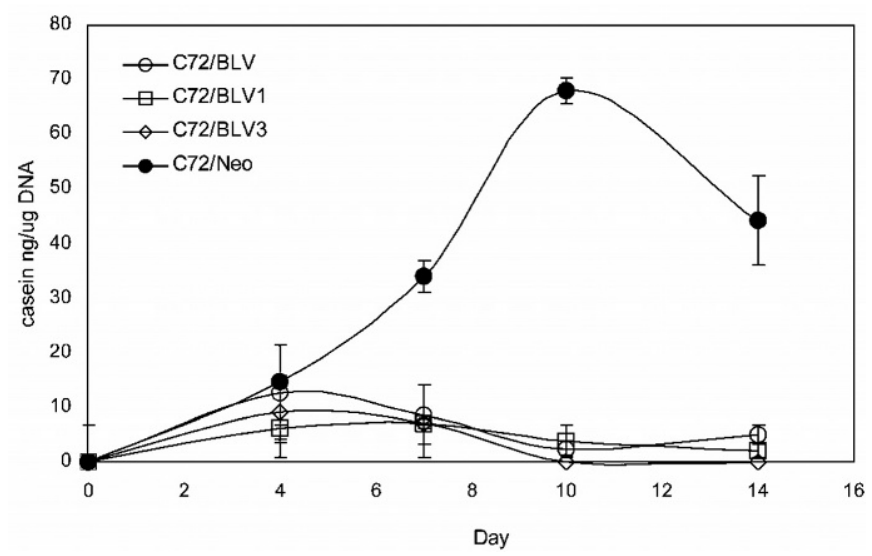

Figure 3. ELISA measurement of $\mathrm{CN}$ in cellular lysates from bovine mammary epithelial cells with and without bovine leukemia virus. Cells were grown on collagen gels in the presence of lactogenic hormones, prolactin, hydrocortisone, and insulin. Cellular lysates were isolated from cultures every 2 to $3 \mathrm{~d}$ and $\mathrm{CN}$-quantified by ELISA using an avidin-biotin-peroxidase detection system. Error bars represent the standard deviation of three replicates. bovine $\mathrm{CN}$ and bovine GAPDH (as a loading control), and mouse CN and mouse GAPDH, were performed on the cDNA resulting from the RT reaction. Figure 5 shows the amounts of CN mRNA for each cell line.

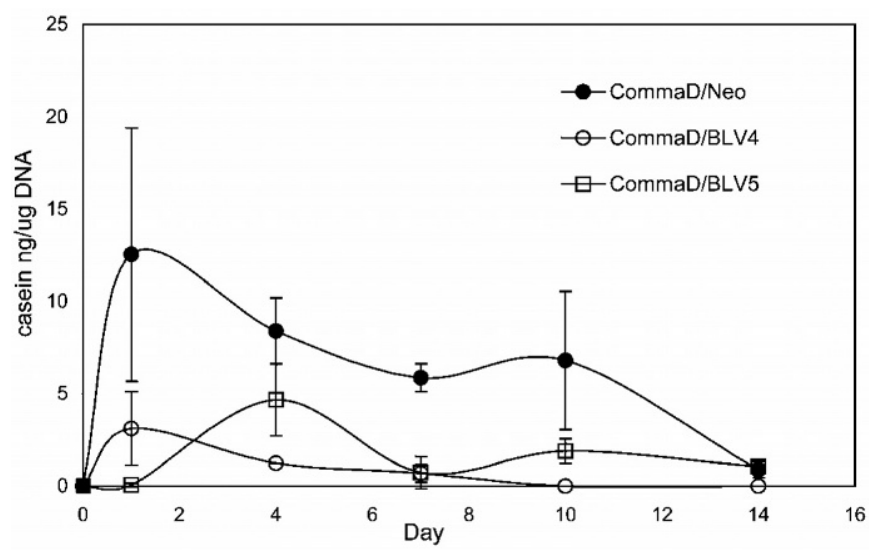

Figure 4. ELISA measurement of $\mathrm{CN}$ in cellular lysates from mouse mammary epithelial cells with and without bovine leukemia virus. Cells were grown on collagen gels in the presence of lactogenic hormones, prolactin, hydrocortisone, and insulin. Cellular lysates were isolated from cultures every 2 to $3 \mathrm{~d}$ CN-quantified by ELISA using an avidin-biotin-peroxidase detection system. Error bars represent the standard deviation of three replicates. 

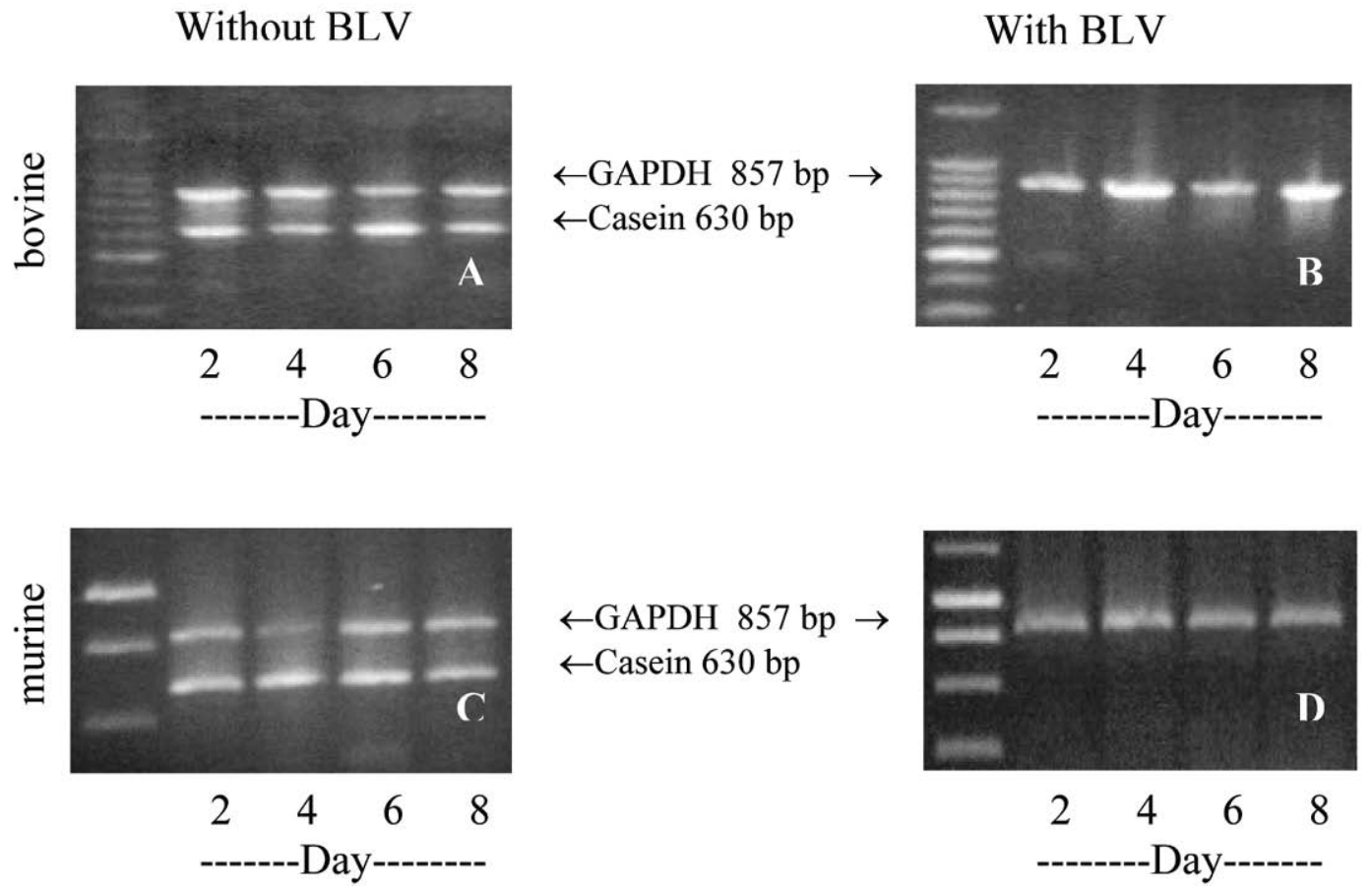

Figure 5. Reverse transcriptase (RT) PCR measurement of CN transcripts in mammary cells with and without bovine leukemia virus (BLV). Cells were grown on collagen gels in the presence of lactogenic hormones, prolactin, hydrocortisone, and insulin. Total RNA was isolated from cultures every $2 \mathrm{~d}$ and the amount of CN mRNA present quantified by RT-PCR. (A) C72/Neo; (B) RT-PCR representative of all bovine mammary cells with BLV: C72/BLV, C72/BLV1, C72/BLV3; (C) Comma D/Neo; and (D) RT-PCR representative of all mouse mammary cells with BLV: Comma D/BLV4, Comma D/BLV5. Lane 1 of gels A and B is a 1-kb marker. Lane 1 of gels C and D is a 100-bp marker.

Control bovine cells $\mathrm{C} 72 / \mathrm{Neo}$ (Figure 5A) produced significant amounts of CN mRNA throughout time in culture, whereas all bovine cells with BLV (Figure 5B) produced barely detectable amounts of $\mathrm{CN}$ mRNA. The Comma D/Neo cells (Figure 5C) also produced significant amounts of CN mRNA in the differentiating hormonal milieu. However, the Comma D/BLV4 and Comma D/BLV5 cells (Figure 5D) produced barely detectable amounts of $\mathrm{CN}$ mRNA.

\section{DISCUSSION}

Until recently, it was thought that the only target cells of BLV infection were B-lymphocytes in which BLV could cause a persistent lymphocytosis or leukemia. But because BLV has also been found in endothelial (Rovnak et al., 1991) and mammary epithelial cells (Buehring et al., 1994a), as well as T-lymphocytes and monocytes (Stott et al., 1991; Heeney et al., 1992), it could be having effects on multiple cell types. This study has demonstrated that BLV can have a cellular effect on mammary epithelial cells by inhibiting their ability to produce $\mathrm{CN}$ in vitro.

There have been numerous studies on the effects of BLV on milk production, but all of these studies looked at whole herds and examined variables such as total milk production, fat content of milk, and days milking. The results were varied. Brenner et al. $(1989,1990)$ and D'Angelino et al. (1998) found a decrease in total milk production in BLV seropositive cows vs. seronegative herdmates. Others have found no difference in milk production between seropositive and seronegative herdmates (Huber et al., 1981; Jacobs et al., 1991). In addition, others have examined the effects of persistent lymphocytosis, a B-cell lymphoproliferative disorder caused by BLV, on milk production traits and have found a decrease in fat production in cows with persistent lymphocytosis compared with healthy herdmates (Da et al., 1993). One study reported a difference in milk production that was dependent on lactation history: BLV-positive cows had higher milk production in the first two lactations, but lower milk production in subsequent lactations, compared to BLV-negative herdmates (Langston et al., 1978).

In our study, the effect of BLV was examined at a cellular rather than organismal or herd level. Bovine leukemia virus significantly altered the growth properties of mammary epithelial cells. The induced changes are known to be associated with cellular transformation in vitro, that is, higher growth rate, 
increased saturation density, and an increased doubling level (Freshney, 2000). In fact, the cells have been immortalized by BLV, and grow continuously in culture without senescing, whereas normal bovine mammary epithelial cells from explants senesce after 20 to 40 doublings (Buehring et al., 1994b). This is also the case with HTLV tax, which can immortalize human T-lymphocytes in culture (Robek and Ratner, 2000). However, the BLV transfected cells are not fully transformed, as they do not grow in soft agar, an in vitro marker of fully transformed cells (Freshney, 2000). This is consistent with the results of Willems et al. (1990) who showed that the product of the BLV tax gene has the ability to immortalize primary fibroblasts in culture, but needs the help of another transforming oncogene, such as ras, to fully transform the cells, that is, make them tumorigenic in nude mice. As such, tax can be classified in the group of immortalizing oncogenes, which include the adenovirus E1A protein, c-myc genes, E6 and E7 of oncogenic human papillomavirus strains, the polyomavirus large-T antigen, and the E6 protein of bovine papillomavirus (Cerni et al., 1989; Willems et al., 1990; Ratsch et al., 2001). In addition to tax, the $X$ region of the BLV genome also codes for another protein, G4, which likewise has oncogenic potential in vitro (Kerkhofs et al., 1998). Specifically, the G4 protein also has the ability to immortalize fibroblasts in culture, but not fully transform them into tumorigenic cells. Surprisingly, coexpression of G4 and tax does not fully transform cells either, but instead only immortalizes the cells, indicating that these two proteins do not synergize to make cells fully malignant (Kerkhofs et al., 1998). Unlike the coexpression of tax with H-ras, which fully transforms cells, coexpression of G4 with H-ras only fully transforms approximately one-third of the cells, indicating only a slight ability to cooperate with other oncogenes for transformation (Kerkhofs et al., 1998). Immortalization is considered to be an early but necessary step in the process of malignant transformation, and this ability to grow infinitely allows the cell to accumulate other mutations that permit malignant transformation (Ratsch et al., 2001). There is evidence that BLV may inhibit certain pathways of DNA repair, thus fostering the accumulation of potentially carcinogenic insults over a long period of time (Philpott and Buehring, 1999). The change in growth properties conferred by BLV to mammary cells in our study could conceivably affect overall milk production in BLV-infected herds. An increase in growth rate and longevity would increase the total number of cells available to produce milk and might increase overall milk yield. We have not subjected our BLV-altered mammary cells to secondary carcinogenic insults to determine whether they would develop the ability to grow in soft agar or produce tumors in nude mice. Likewise, analogous situations are hard to find in vivo because mammary cancer in cows is quite rare, only 41 cases having been documented since 1902 (Petrites-Murphy, 1992).

In contrast to the changes found in cell growth and longevity, no changes were seen in steroid hormone receptor levels and affinities for estrogen, progesterone, and glucocorticoids. The increased levels of estrogen and progesterone during pregnancy induces proliferation of mammary epithelial cells, and the abrupt elevation of glucocorticoids at parturition contributes to the final maturation of mammary epithelium in preparation for lactogenesis (Cowie et al., 1980). An increased level or affinity of receptors for these steroids could increase mammary epithelial cell mitogenesis and/or lactogenesis, and result in more milk production. With a decreased level or affinity, the opposite may occur. Our results indicating no essential change in estrogen, progesterone, or glucocorticoid receptor status suggests that BLV probably does not have the ability to change the responsiveness of the cells to these steroid hormones. The exception is the clone $\mathrm{C} 72$ / BLV3, which had a significantly higher level of estrogen receptors with a normal affinity, but whose proliferation was not stimulated by estrogen. This finding is not unexpected since other researchers found that estrogen did not stimulate growth of mammary epithelial cells in culture (Woodward et al., 2000). It is likely that our in vitro conditions were appropriate to adequately test steroid receptor levels and affinity. The maintenance medium used was supplemented with phenol red, which has estrogenic activity, and FBS, which has levels of steroid hormones sufficient to prime the respective cellular receptors (Katzenellenbogen et al., 1987). The results of the whole cell progesterone receptor binding assay agree with those of other researchers who grew their cells under similar conditions (Katzenellenbogen et al., 1987).

The most dramatic and unexpected result of our study is the effect of BLV on CN production. Neither the bovine nor murine cell line transfected with BLV could produce significant amounts of $\mathrm{CN}$, and this inhibition was determined to be at the level of transcription, as confirmed by RT-PCR. Transformation of a normal cell to a cancer cell by a carcinogenic agent is known to block normal differentiation of the cell (von Wangenheim and Peterson, 1998). Synthesis of milk occurs only in the fully differentiated cell (Cowie et al., 1980), one that exhibits the specific structure and function characteristics of its tissue type-in this case, milk production. Bovine leukemia virus is somehow blocking the ability of this cell to produce milk, and this may be through an inhibition of overall differentiation. 
This is in contrast to what is known about another retrovirus found in mammary epithelial cells, mouse mammary tumor virus. Differentiation of the mouse mammary epithelial cell increases production of the virus by the cells (Durban et al., 1990), and CN production by these cells is retained (Enami et al., 1979). However, BLV has some significant differences from mouse mammary tumor virus, even though they are both retroviruses. Mouse mammary tumor virus transforms by insertion mutagenesis, dramatically increasing transcriptional level of relatively few proto-oncogenes, whereas the BLV oncoprotein, Tax, interacts with multiple cellular proteins and transcription factors that control expression of numerous genes (Kettman et al., 1994). Tax could conceivably be interacting with one or more transcription factors responsible for milk protein synthesis, thereby altering expression of milk protein genes such as the coactivators p300/CBP. P300 is closely related to the cAMP responsive element binding factor (CREB) binding protein (CBP). These proteins serve as coactivators for phosphorylated CREB (Hottiger and Nabel, 2000). Several investigators have shown that both HTLV Tax and BLV Tax interact with the CREB/ATF-1 family of transcriptional activators (Zhao and Giam, 1992; Boros et al., 1995). It has been shown that the tax protein of HTLV interacts with CBP, and this interaction is necessary, but not sufficient for maximum viral transcription (Harrod et al., 2000). The p300/CBP family of coactivators are relevant to expression of milk protein genes because they interact with Stat5, a member of the Stat (signal transducer and activator of transcription) family of transcriptional activators (Burdon et al., 1994). Originally known as mammary gland factor, Stat5 is induced by prolactin in mammary epithelial cells (Gouilleux et al., 1994). P300/CBP enhances the lactational response of mammary epithelial cells to prolactin by interacting and activating Stat5 (Pfitzner et al., 1998). Because HTLV Tax can bind p300/CBP, it is probable that BLV Tax can also. It has been shown previously that adenovirus E1A can bind p300/CBP and abrogate Stat5-induced transcription (Look et al., 1998). Tax may be doing this in mammary epithelial cells, the result being that expression of genes induced by Stat5, for example, CN, is inhibited.

The results of this study show that BLV may not be an innocuous factor in the biology of infected cows. Even though only approximately half of infected cows develop any clinical manifestation of BLV infection, viz. persistent lymphocytosis and leukemia (Kettman et al., 1994), it may still be having other deleterious effects on the biology of the animal. Data presented here suggest that, in addition to transforming B-lymphocytes, BLV has the inherent capability to start the mammary epithelial cell on the path towards malignant transformation and to affect its normal differentiation. In light of the evidence that BLV can infect mammary epithelial cells in vivo (Buehring et al., 1994a), it is not impossible that the same changes seen in our study in vitro may be happening in vivo, and BLV could be affecting milk production in domestic dairy cattle. If this proved to be correct, eradication of BLV from US dairy herds is an issue that might need more attention and support. Further research based on the results of this study could have a major impact on how the dairy industry manages BLV-infected cattle.

\section{ACKNOWLEDGMENTS}

We would like to thank Ronald Schultz and Patrick Kramme, University of Wisconsin, Madison, for the bovine mammary explant; Charlotte Kaetzel, University of Kentucky, Lexington, for the antibody to mouse CN; Mary Helen Barcellos-Hoff, Lawrence Berkeley National Laboratory, for the Comma-D cell line; Jim Murray, University of California, Davis for mouse milk; James Casey, Cornell University for the pBLV plasmid; and Isabel Cludts, Free University of Brussels, for the pSVneo plasmid. Special thanks to Gary Firestone, Leonard Bjeldanes, Linda Kingsbury, and K. Yeon Choi of the University of California, Berkeley, for their advice and technical support. Also special thanks to Manfred Lee and Walter Dunn for technical support. This work was supported in part by grants from the University of California, Berkeley, Committee on Research. Deborah Motton was supported by a Soroptomist International Founder Region Fellowship, University of California, Berkeley Chancellor's Opportunity Fellowship, and a University of California, Berkeley Mentored Research Fellowship.

\section{REFERENCES}

Boros, I. M., F. Tie, and C. Z. Giam. 1995. Interaction of bovine leukemia virus transactivator Tax with bZip proteins. Virology 214:207-214.

Brenner, J., M. Van-Haam, D. Savir, and Z. Trainin. 1989. The implication of BLV-infection in productivity, reproductive capacity and survival rate or a dairy cow. Vet. Immun. Immunopath. 22:299-305

Brenner, J., I. Rosenthal, S. Bernstein, and Z. Trainin. 1990. The fat content of milk from dairy cattle infected with bovine leukosis virus. Vet. Res. Commun. 14:167-171.

Buehring, G. C. 1990. Culture of mammary epithelial cells from bovine milk. J. Dairy Sci. 78:956-963.

Buehring, G. C., P. M. Kramme, and R. D. Schultz. 1994a. Evidence for bovine leukemia virus in mammary epithelial cells of infected cows. Lab. Invest. 71:359-365.

Buehring, G. C., R. L. Neiswander, G. L. Niermann, C. A. Sweeney, M. F. McGrath, and F. L. Schanbacher. 1994b. Lifespan of bovine mammary epithelial cells in vitro. In Vitro Cell Dev. Biol. 30A:95-96. 
Burdon, T. G., J. Demmer, A. J. Clark, and C. J. Watson. 1994. The mammary factor MPBF is a prolactin-induced transcriptional regulator which binds to STAT factor recognition sites. FEBS Lett. 350:177-182.

Cerni, C., B. Binetruy, J. T. Schiller, D. R. Lowy, G. Meneguzzi, and F. Cuzin. 1989. Successive steps in the process of immortalization identified by transfer of separate bovine papillomavirus genes into rat fibroblasts. Proc. Natl. Acad. Sci. USA $86: 3266-3270$.

Cowie, A. T., I. A. Forsyth, and I. C. Hart. 1980. Hormonal Control of Lactation. Springer-Verlag, New York.

Da, Y., R. D. Shanks, J. A. Stewart, and H. A. Lewin. 1993. Milk and fat yields decline in bovine leukemia virus-infected Holstein cattle with persistent lymphocytosis. Proc. Natl. Acad. Sci. USA 90:6538-6541.

D’Angelino, J. L., M. Garcia, and E. H. Birgel. 1998. Productive and reproductive performance in cattle infected with bovine leukosis virus. J. Dairy Res. 65:693-695.

Danielson, K. G., C. J. Oborn, E. M. Durban, J. S. Butel, and D. Medina. 1984. Epithelial mouse mammary cell line exhibiting normal morphogenesis in vivo and functional differentiation in vitro. Proc. Natl. Acad. Sci. USA 81:3756-3760.

Derse, D., and J. W. Casey. 1986. Two elements in the bovine leukemia virus long terminal repeat that regulate gene expression. Science 231:1437-1440.

Detilleux, J. C., A. E. Freeman, and L. D. Miller. 1991. Comparison of natural transmission of bovine leukemia virus in Holstein cows of two genetic lines selected for high and average milk production. Am. J. Vet. Res. 52:1551-1555.

Durban, E. M., J. E. Knepper, D. Medina, and J. S. Butel. 1990. Influence of mammary cell differentiation on the expression of proteins encoded by endogenous BALB/c mouse mammary tumor virus genes. Virus Res. 16:307-323.

Enami, J., J. Yang, and S. Nandi. 1979. Simultaneous production of casein and mammary tumor virus in mouse mammary epithelial cells grown on floating collagen gels. Cancer Lett. 6:99-105.

Freshney, R. I. 2000. Culture of Animal Cells. A Manual of Basic Technique. 4th ed. J. Wiley, Inc., New York, NY.

Gouilleux, F., H. Wakao, M. Mundt, and B. Groner. 1994. Prolactin induces phosphorylation of Tyr694 of Stat5 (MGF), a prerequisite for DNA binding and induction of transcription. EMBO J. 13:4361-4369.

Harrod, R., Y. L. Kuo, Y. Tang, Y. Yao, A. Vassilev, Y. Nakatani, and C. Z. Giam. 2000. p300 and p300/cAMP-responsive elementbinding protein associated factor interact with human T-cell lymphotropic virus type-1 Tax in a multi-histone acetyltransferase/activator-enhancer complex. J. Biol. Chem. 275:1185211857.

Heeney, J., P. Valli, R. Jacobs, and V. Valli. 1992. Evidence for bovine leukemia virus infection of peripheral blood monocytes and limited antigen expression in bovine lymphoid tissue. Lab. Invest. 66:608-617.

Hottiger, M. O., and G. J. Nabel. 2000. Viral replication and the coactivators p300 and CBP. Trends Microbiol. 8:560-565.

Huber, N. L., R. F. DiGiacomo, J. R. Evermann, and E. Studer. 1981. Bovine leukemia virus infection in a large Holstein herd: Prospective comparison of production and reproductive performance in antibody negative and antibody positive cows. Am. J. Vet. Res. 42:1477-1481.

Imagawa, W., Y. Tomooka, S. Hamamoto, and S. Nandi. 1985. Stimulation of mammary epithelial cell growth in vitro: Interaction of epidermal growth factor and mammogenic hormones. Endocrinology 116:1515-1524.

Jacobs, R. M., J. L. Heeney, M. A. Godkin, K. E. Leslie, J. A. Taylor, C. Davies, and V. E. O. Valli. 1991. Production and related variables in bovine leukemia virus-infected cows. Vet. Res. Commun. 15:463-474.

Katzenellenbogen, B. S., K. L. Kendra, M. J. Norman, and Y. Berthois. 1987. Proliferation, hormonal responsiveness, and estrogen receptor content of MCF-7 human breast cancer cells grown in the short term and long-term absence of estrogens. Cancer Res. 47:4355-4360.
Kerkhofs, P., H. Heremans, A. Burny, R. Kettman, and L. Willems. 1998. In vitro and in vivo oncogenic potential of bovine leukemia virus G4 protein. J. Virol. 72:2554-2559.

Kettman, R., A. Burny, I. Callebaut, L. Droogmans, M. Mammerickx, L. Willems, and D. Portetelle. 1994. Bovine leukemia virus. Pages 39-91 in The Retroviridae. Vol. 3. J. A. Levy, ed. Plenum Press, New York, NY.

Langston, A., G. A. A. Ferdinand, R. Ruppanner, G. H. Theilen, S. Drlica, and D. Behymer. 1978. Comparison of production variables of bovine leukemia virus antibody-negative and antibodypositive cows in two California dairy herds. Am. J. Vet. Res. 39:1093-1098.

Look, D. C., W. T. Roswit, A. G. Frick, Y. Gris-Alevy, D. M. Dickhaus, M. J. Walter, and M. J. Holtzman. 1998. Direct suppression of Stat1 function during adenoviral infection. Immunity 9:871880.

Miller, S. A., D. D. Dykes, and H. F. Polesky. 1988. A simple salting out procedure for extracting DNA from human nucleated cells. Nucleic Acids Res. 16:1215.

Mosmann, T. 1983. Rapid colorimetric assay for cellular growth and survival: Application to proliferation and cytotoxicity assays. J. Immunol. Methods 65:55-63.

National Animal Health Monitoring System (NAHMS). 1996. High prevalence of BLV in U.S. dairy herds. Centers for Epidemiology and Animal Health USDA:APHIS:VS, NAHMS, 555 South Howes, Fort Collins, CO 80521. Online. Available: http:// www.aphis.usda.gov/vs/ceah/cahm/Dairy_Cattle/d96blv.htm.

Petrites-Murphy, M. B. 1992. Mammary carcinoma with peritoneal metastasis in a cow. Vet. Pathol. 29:552-553.

Pfitzner, E., R. Jahne, M. Wissler, E. Stoecklin, and B. Groner. 1998. p300/CREB-binding protein enhances the prolactin-mediated transcriptional induction through direct interaction with the transactivation domain of Stat5, but does not participate in the Stat5-mediated suppression of the glucocorticoid response. Mol. Endocrinol. 12:1582-1593.

Philpott, S. M., and G. C. Buehring. 1999. Defective DNA repair in cells with human T-cell leukemia/bovine leukemia viruses: Role of tax gene. J. Natl. Cancer Inst. 91:933-42.

Ratsch, S. B., Q. Gao, S. Srinivasan, D. E. Wazer, and V. Band. 2001. Multiple genetic changes are required for efficient immortalization of different subtypes of normal human mammary epithelial cells. Radiat. Res. 155:143-150.

Robek, M. D., and L. Ratner. 2000. Immortalization of T lymphocytes by human T-cell Leukemia virus type 1 is independent of the Tax-CBP/p300 interaction. J. Virol. 74:11988-11992.

Rovnak J., J. W. Casey, A. L. Boyd, M. A. Gonda, and G. L. Cockerell. 1991. Isolation of bovine leukemia virus infected endothelial cells from cattle with persistent lymphocytosis. Lab. Invest. 65:192-202.

Sambrook, J., E. L. Fritsch, and T. Maniatis. 1989. Molecular Cloning: A Laboratory Manual. 2nd ed. Cold Spring Harbor Press, Cold Spring Harbor, NY.

Southern, P. J., and P. Berg. 1982. Transformation of mammalian cells to antibiotic resistance with a bacterial gene under control of the SV40 promoter. J. Mol. Appl. Genet. 1:327-334.

Stott, M. L., M. C. Thurmond, S. J. Dunn, B. I. Osburn, and J. L. Stott. 1991. Integrated bovine leukosis proviral DNA in T helper and $\mathrm{T}$ cytotoxic/suppressor lymphocytes. J. Gen. Virol. 72:307-315.

Talhouk, R. S., R. L. Neiswander, and F. L. Schanbacher. 1993. Morphological and functional differentiation of cryopreserved lactating bovine mammary cells cultured on floating collagen gels. Tissue Cell 25:799-816.

Thurmond, M. C. 1987. Economics of enzootic bovine leukosis. Pages 71-84 in Developments in Veterinary Virology: Enzootic Bovine Leukosis and Bovine Leukemia Virus. A. Burny and M. Mammerickx, ed. Martinus Nijhollf Publishing, Boston, MA.

von Wangenheim, K. H., and H. P. Peterson. 1998. Control of cell proliferation by progress in differentiation: Clues to mechanisms of aging, cancer causation and therapy. J. Theor. Biol. 193:663-678 
Willems, L., C. Grimonpont, P. Kerkhofs, C. Capiau, D. Gheysen, K. Conrath, R. Roussef, R. Mamoun, D. Portetelle, A. Burny, E. Adam, L. Lefebvre, J. C. Twizere, H. Heremans, and R. Kettman. 1998. Phosphorylation of bovine leukemia virus Tax protein is required for in vitro transformation but not for transactivation. $16: 2165-2176$.

Willems, L., H. Heremans, G. Chen, D. Portetelle, A. Billiau, A. Burny, and R. Kettman. 1990. Cooperation between bovine leukemia virus transactivator protein and $\mathrm{H}$-ras oncogene product in cellular transformation. EMBO J. 9:1577-81.
Woodward, T. L., J. Xie, J. L. Fendrick, and S. Z. Haslem. 2000. Proliferation of mouse mammary epithelial cells in vitro: Interactions among epidermal growth factor, insulin-like growth factor I, ovarian hormones, and extracellular matrix. Endocrinology 141:3578-3586.

Zhao, L. J., and C. Z. Giam. 1992. Human T-cell lymphotropic virus type I (HTLV-I) transcriptional activator, Tax, enhances CREB binding to the HTLV-I 21-base-pair repeats by protein-protein interaction. Proc. Natl. Acad. Sci. USA 89:7070-7074. 